\title{
Enhanced production of Labrador Sea Water in 2008
}

\author{
Igor Yashayaev $^{1}$ and John W. Loder ${ }^{1}$ \\ Received 29 September 2008; revised 5 November 2008; accepted 13 November 2008; published 10 January 2009
}

[1] A May 2008 oceanographic survey of the Labrador Sea and recent Argo float profiles have revealed that convective overturning extended to a depth of about $1600 \mathrm{~m}$ during the winter of 2008 , resulting in the production of a large "year class" of Labrador Sea Water. This convection was the deepest since 1994, and substantially exceeded the convection to $500-1100 \mathrm{~m}$ in the past few years in both the Labrador and Irminger Seas. The resultant $0.2^{\circ} \mathrm{C}$ cooling of the intermediate-depth waters in the Labrador Sea has disrupted a steady warming of these waters since 1994 . The cumulative heat loss from the ocean to the atmosphere during the 2007-2008 cooling season was the largest since the mid-1990s and exceeded the 2000-2007 mean by about $50 \%$. This indicates that enhanced atmospheric cooling, apparently associated with below-normal air temperatures in the region, was the predominant factor contributing to the enhanced LSW production in 2008. Citation: Yashayaev, I., and J. W. Loder (2009), Enhanced production of Labrador Sea Water in 2008, Geophys. Res. Lett., 36, L01606, doi:10.1029/ 2008 GL036162.

\section{Introduction}

[2] The Labrador Sea is the coldest and freshest basin of the North Atlantic Ocean and the source of the intermediatedepth water mass - Labrador Sea Water (LSW) [Lazier et al., 2002; Talley and McCartney, 1982]. LSW is formed by deep convection (overturning) caused by strong surface cooling during severe winters [Clarke and Gascard, 1983] and spreads throughout the entire North Atlantic [Yashayaev et al., 2007a, hereinafter referred to as Y2007a; Yashayaev et al., 2007b, hereinafter referred to as Y2007b]. It plays an important role in the exchange of heat, freshwater and biogeochemical properties between the atmosphere and the deep ocean, affecting the water masses, circulation, climate and ecosystems of the subpolar and other North Atlantic basins (see overviews by Y2007a and Y2007b). Its main equatorward transit or export route is associated with the upper portion of the Deep Western Boundary Current, but a significant portion of newly-formed LSW remains in the subpolar gyre, circulating and mixing with the other intermediate and deep waters occupying the deep subpolar basins.

[3] In this paper, we report on observations of enhanced production of LSW during the winter of 2008 which are expected to have implications for broader hydrographic, circulation and climate variability in the Atlantic.

\footnotetext{
${ }^{1}$ Fisheries and Oceans Canada, Bedford Institute of Oceanography, Dartmouth, Nova Scotia, Canada.
}

Copyright 2009 by the American Geophysical Union. 0094-8276/09/2008GL036162

\section{Data Sources}

[4] The Bedford Institute of Oceanography (BIO) of Fisheries and Oceans Canada (DFO) has been conducting an annual spring survey of the Labrador Sea for the past two decades, as part of its ocean climate monitoring program. Systematic high-quality physical, chemical, and biological observations are collected on the AR7W line (initiated in the World Ocean Circulation Experiment) extending from the Labrador Shelf to the Greenland Shelf. The full watercolumn sampling performed on this line monitors the subpolar gyre in this region, as well as the entire deep limb of the Atlantic Meridional Overturning Circulation (AMOC) comprising LSW, Northeast Atlantic Deep Water (NEADW) and Denmark Strait Overflow Water (DSOW) [Yashayaev, 2007, hereinafter referred to as Y2007; Yashayaev and Dickson, 2008]. Temperature and salinity data from BIO's occupation of the AR7W line during 23-29 May 2008, together with those from previous years, are the primary basis for this report. These data have been quality-controlled following procedures used in other recent analyses (e.g., Y2007).

[5] A second important in situ dataset used here comes from the international Argo program (http://www.argo.ucsd. edu), which presently has about 3000 profiling floats providing real-time monitoring of temperature and salinity in the upper $2000 \mathrm{~m}$ of the world ocean. Observations from the Argo floats since 2002 nicely complement the annual snapshot from the AR7W line by providing continuous temporal coverage of both the Labrador Sea and adjacent basins, and resolving major seasonal water-mass developments (albeit at coarse spatial resolution). The Argo data used here were obtained from the World Global Data Assembly Centers and quality controlled by analyzing deviations from spatially and temporally binned medians. They were then used to create "composite" spatially-averaged time series of vertical temperature and salinity structure for the regions of the Labrador and Irminger Seas affected by deep convection (Y2007a and Y2007b).

[6] Time series of net heat flux across the sea surface in the Labrador Sea since 2002 were computed as a sum of latent and sensible heat fluxes and short- and long-wave radiation from daily-mean data obtained from the Reanalysis Project of the U.S. National Center for Environmental Prediction (NCEP) (http://www.cdc.noaa.gov).

\section{Recent LSW Variability From AR7W}

[7] In contrast to May 2007, the May 2008 occupation of the AR7W line reveals an enhanced mixed layer over the $400-1600 \mathrm{~m}$ depth range in the west-central Labrador Sea, with potential temperatures $<3.4^{\circ} \mathrm{C}$, salinities $<34.86$ and potential densities $<27.75$ (Figure 1). Evidence in later sections indicates that this layer was formed by deep 

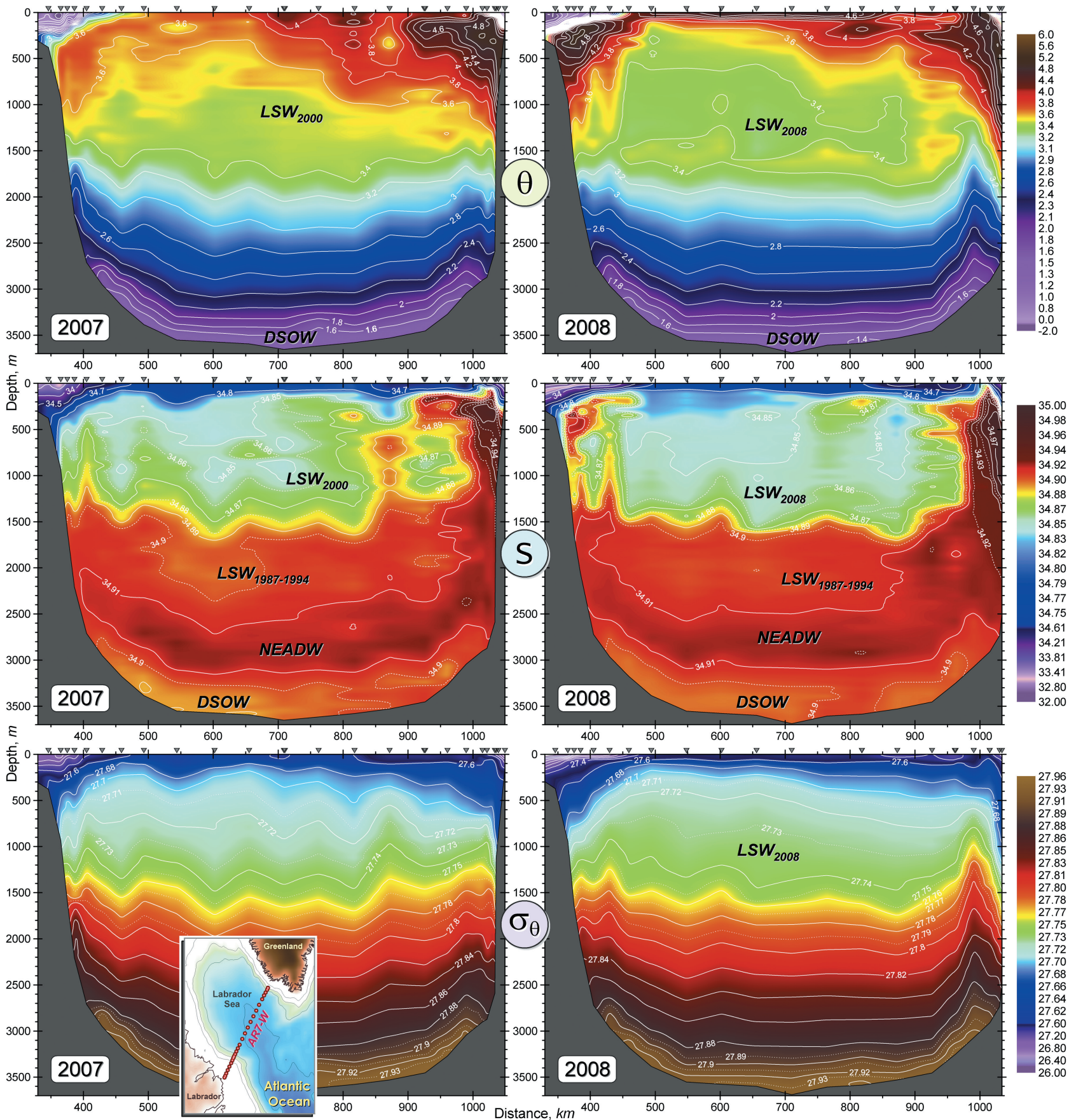

Figure 1. Potential temperature $(\theta)$, salinity $(\mathrm{S})$ and potential density $\left(\sigma_{\theta}\right)$ distributions on the AR7W line (inset map at bottom) in (left) May 2007 and (right) May 2008. The Labrador Shelf is on the left.

convection driven by atmospheric forcing in JanuaryMarch 2008. By May, this winter mixed layer was already capped by a relatively warm $\left(\sim 4^{\circ} \mathrm{C}\right)$ and fresh seasonal surface layer associated with horizontal advection and airsea heat fluxes. We refer to this newly-formed intermediatedepth layer as the 2008 year class of LSW, denoted as $\mathrm{LSW}_{2008}$ following the approach of Y2007. The layer becomes thinner from west to east along the section. The addition of this new layer of $\mathrm{LSW}_{2008}$ has resulted in an average cooling by more than $0.1^{\circ} \mathrm{C}$ of the $300-1600 \mathrm{~m}$ layer across the entire central Labrador Sea since 2007.
[8] Beneath $\mathrm{LSW}_{2008}$ between $\sim 1600$ and $\sim 1700 \mathrm{~m}$, there is a thin, slightly warmer layer with temperatures about $3.5^{\circ} \mathrm{C}$. This is likely a mixture of Icelandic Slope Water and remnant LSW from previous years (Y2007a and Y2007b) that had been steadily warming over the past decade. The 2007 and 2008 sections also show the other two components of the AMOC's lower limb passing through the Labrador Sea's abyss: salty NEADW and cold DSOW which originate, respectively, from the two major dense Arctic overflows entering the Iceland Basin and the Irminger Sea [Yashayaev and Dickson, 2008]. 


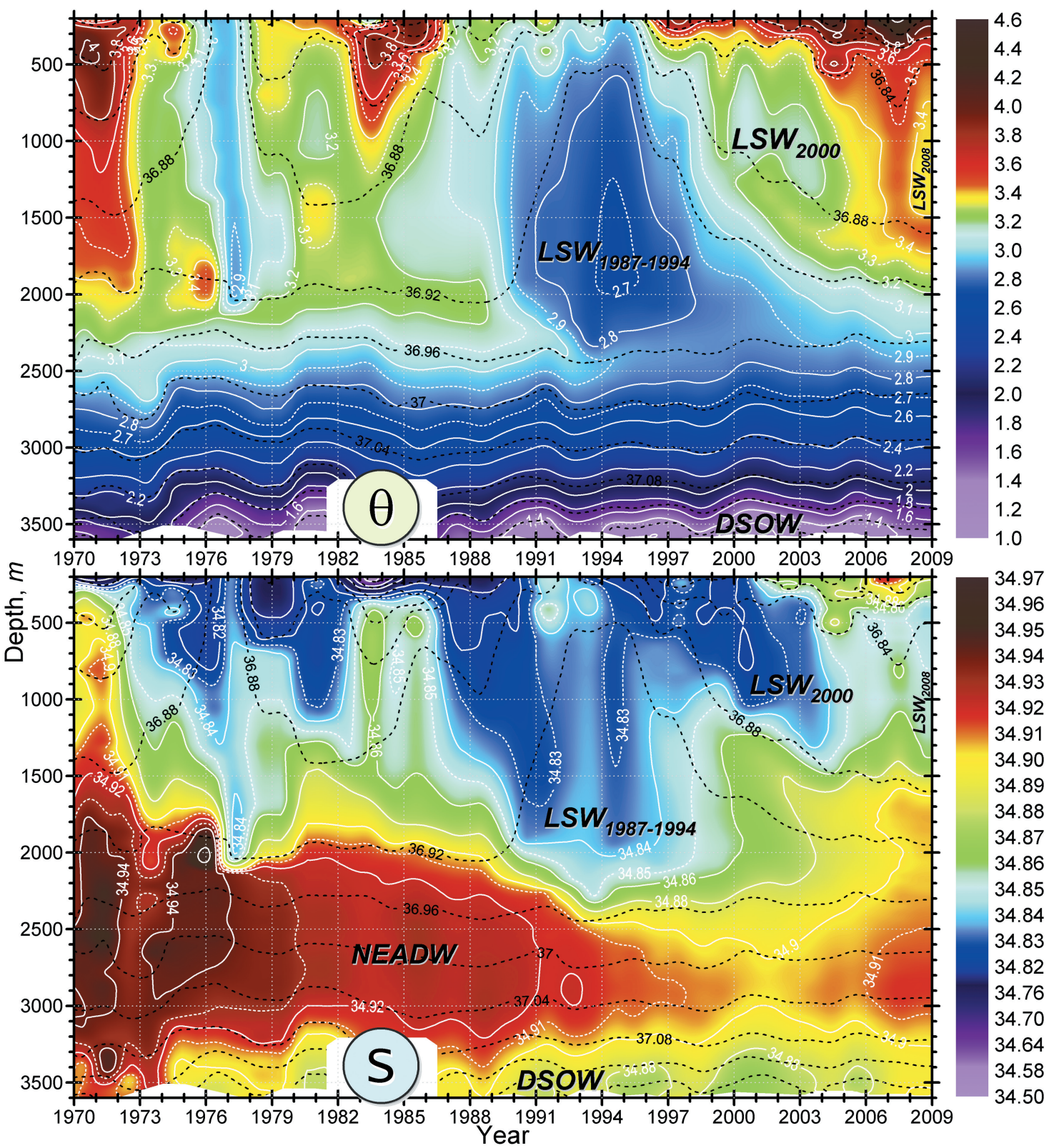

Figure 2. Time evolution of potential temperature $(\theta)$ and salinity $(\mathrm{S})$ in the central Labrador Sea. Annual vertical property profiles were constructed by applying isopycnal averaging to all measurements in water depths greater than $3250 \mathrm{~m}$ and within $150 \mathrm{~km}$ of the AR7W line, following Y2007. The potential density anomaly (ref. $2000 \mathrm{db}$ ) isolines (dashed) reflect changes in the density of various LSW classes.

[9] To place the 2007 and 2008 observations of LSW in historical context, we show the 1970-2008 evolution of temperature and salinity in the central Labrador Sea (Figure 2). The waters of the Labrador Sea have undergone remarkable changes over the past few decades, including two previous periods of major LSW production during the past 25 years (Y2007).

[10] The first period, 1987-1994, was characterized by progressive development of the record dense and voluminous $\mathrm{LSW}_{1987-1994}$ class through a succession of severe winters [Lazier et al., 2002; Y2007]. This class, which extended to $2400 \mathrm{~m}$ depth, has declined significantly since the mid-1990s, associated with warmer and saltier waters from the other subpolar basins entering and filling the depth range above its remnants. Although diminished in volume and signatures (e.g., S-min, $\mathrm{O}_{2}$-max), $\mathrm{LSW}_{1987-1994}$ can still be identified in the 1800-2300 m depth range in the 2007 and 2008 sections (Figure 1, middle).

[11] The second recent period of LSW development, 2000-2003, resulted in the $\mathrm{LSW}_{2000}$ class that can be identified in the 2007 section near $1000 \mathrm{~m}$ (Figure 1). Formed in 2000 and possibly renewed between 2001 and 2003, extending to $1300 \mathrm{~m}$ depth (Figure 2), this class has been seen spreading across the North Atlantic at depths shallower than its colder and denser $\left(\mathrm{LSW}_{1987-1994)}\right.$ precursor (Y2007a and Y2007b).

[12] Relatively mild winters in recent years have led to a reduction of newly-ventilated water in the Labrador Sea 
(convection shallower than $700 \mathrm{~m}$ in 2007, Figure 1) with the upper $2000 \mathrm{~m}$ continuing to warm and increase its salinity (note the period 2000-2007 in Figure 2, and also compare Figure 1 with Y2007's Figure 3).

[13] Another noteworthy feature in the May 2008 AR7W section is the warm and salty water in the 200-1000 m depth range over the Labrador Slope (Figure 1). This is the remnant of Irminger Current water (IC) which enters the Labrador Sea around the southern tip of Greenland from the Irminger Sea, and flows cyclonically around the basin before exiting on the Labrador side. Note that, in the 2007 section, this water was 1.2 to $1.5^{\circ} \mathrm{C}$ colder over the Labrador Slope than over the Greenland Slope, whereas in 2008, the remnant IC water on the Labrador side had a comparable temperature to the incoming IC water. The 2008 case with little apparent modification of IC water during its passage around the Labrador Sea is unique in the recent historical record. Temperature values averaged over the 200-800 m layer on the eastern and western sides of AR7W during 1987-2005 (see Y2007, Figure 8) indicate a $0.7-1.7^{\circ} \mathrm{C}$ range for the temperature decrease of IC water while circuiting the Labrador Sea, compared to no sign of cooling in 2008. Assuming an average speed in the $10-20 \mathrm{~cm} / \mathrm{s}$ range, a rough estimate of the transit time between the eastern and western sides of the AR7W line is 2-4 months which indicates that the IC water observed on the Labrador side in late May 2008 would have been moving around the Labrador Sea since January-March 2008. This raises the possibility that it may have been connected to the wintertime convection (see later).

\section{Recent Variability in the Labrador and Irminger Seas From Argo Floats}

[14] Near-real-time temperature and salinity profiles available from the Argo program prior to the May 2008 survey showed enhanced convection in the Labrador Sea during the winter of 2008 (Figure 3). The spatial and temporal coverage of the region by Argo floats since 2002 is adequate to resolve the seasonal-depth evolution of hydrographic variability in the central Labrador Sea down to $2000 \mathrm{~m}$.

[15] The 2008 winter-spring Argo observations from the Labrador Sea show the development of a relatively cold (dark blue), fresh (light blue) and homogeneous mixed layer from an initial depth of $\sim 100 \mathrm{~m}$ in January to a depth of $\sim 1600 \mathrm{~m}$ in late March (one profile suggested a depth greater than $1800 \mathrm{~m}$ ). This layer had greater depth penetration than the mixed layers formed since 2002. This newlyformed mixed layer is the origin of the $\mathrm{LSW}_{2008}$ class identified in the May AR7W survey. The Argo observations show that the warmer and fresher seasonal surface layer re-appeared in April and was further developed by the time of the May hydrographic survey.

[16] The Argo temperature-salinity time series indicate that deep convection in the central Labrador Sea extended to depths of about $700-1100 \mathrm{~m}$ during the winters of $2001-$ 2007 , with the exception of $1200-1300 \mathrm{~m}$ in 2003. During this period, the average temperature of the 1000-1500 m layer was slowly and steadily warming (Figure 4a), as the remnant $\mathrm{LSW}_{2000}$ class was diffusing and being replaced by waters from elsewhere. The deep convection in 2008 resulted in an abrupt end to this trend, with the temperature of this layer dropping by about $0.2^{\circ} \mathrm{C}$ due to the massive production of $\mathrm{LSW}_{2008}$.

[17] The Argo observations (Figure 3) also show the seasonal evolution of the hydrography in the Irminger Sea which has previously been shown to be interconnected with the Labrador Sea at various depths (Y2007a and Y2007b), and also proposed to be an isolated area of deep convection [Pickart et al., 2003]. The winter deepening of this area's surface mixed layer is also apparent, but it can be seen that convection there did not extend below $800 \mathrm{~m}$ in 2008 nor in any other years of the Argo record. There is however a layer between 700 and $1200 \mathrm{~m}$ in the Irminger Sea that intermittently showed temperature and salinity minima particularly in the 2002-2005 period, but there is no indication that it had a local origin connected to the sea surface (note the persistent warmer water in the upper $500 \mathrm{~m}$ ). On the other hand, the properties of this layer are consistent with those expected for remnant LSW, and in particular $\mathrm{LSW}_{2000}$ which was formed during 2000-2003 and would have been expected to reach the Irminger Sea within 1-2 years. It can also be seen that $\mathrm{LSW}_{2008}$ had not arrived in the Irminger Sea as of October 2008, which is consistent with the 1-2 yr transit time estimates based on previous annual surveys of the major subpolar basins (Y2007a and Y2007b).

\section{Role of Atmospheric Forcing}

[18] Total surface heat fluxes (positive upward or outgoing) constructed from the NCEP flux components were averaged over an area of the Labrador Sea closely matching the region used to create the Argo time series in Figure 3. Time series of cumulative heat transfer (CHT) from the ocean, computed by progressive integration of the total surface flux from the time in each year when heat loss started to occur and continuing until it ended (fall-winter), are shown in Figure $4 \mathrm{~b}$ (blue). The integration was then continued through the portion of the year when heat transfer into the ocean was occurring (spring-summer), partially offsetting the earlier cumulative heat loss. This resulted in the pink portions of the CHT curves in Figure $4 \mathrm{~b}$ which complete the cooling-heating cycle for each year.

[19] The CHT in each year can be compared with ocean heat content $(\mathrm{HC})$ from the Labrador Sea Argo profiles (Figure 3). To facilitate this comparison, the HC values are referenced to those at the start date of cooling and then reversed in sign to construct the relative heat content (RHC) series shown in Figure $4 \mathrm{~b}$. The blue/red RHC curves correspond to the periods with decreasing/increasing $\mathrm{HC}$ (net ocean cooling/warming).

[20] The comparison of CHT with RHC confirms the predominant importance of the surface fluxes to temperature variability in the Labrador Sea and, to a lesser extent (because of uncertainty in the NCEP fluxes), also indicates an important contribution from horizontal advective-diffusive exchange. The fall-winter of 2007-2008 had the largest cumulative heat loss from the ocean to the atmosphere of the seven years examined, with magnitude about $50 \%$ above the 2002-2007 mean. This indicates that an anomalously high level of atmospheric cooling led to the enhanced production of LSW in 2008. 


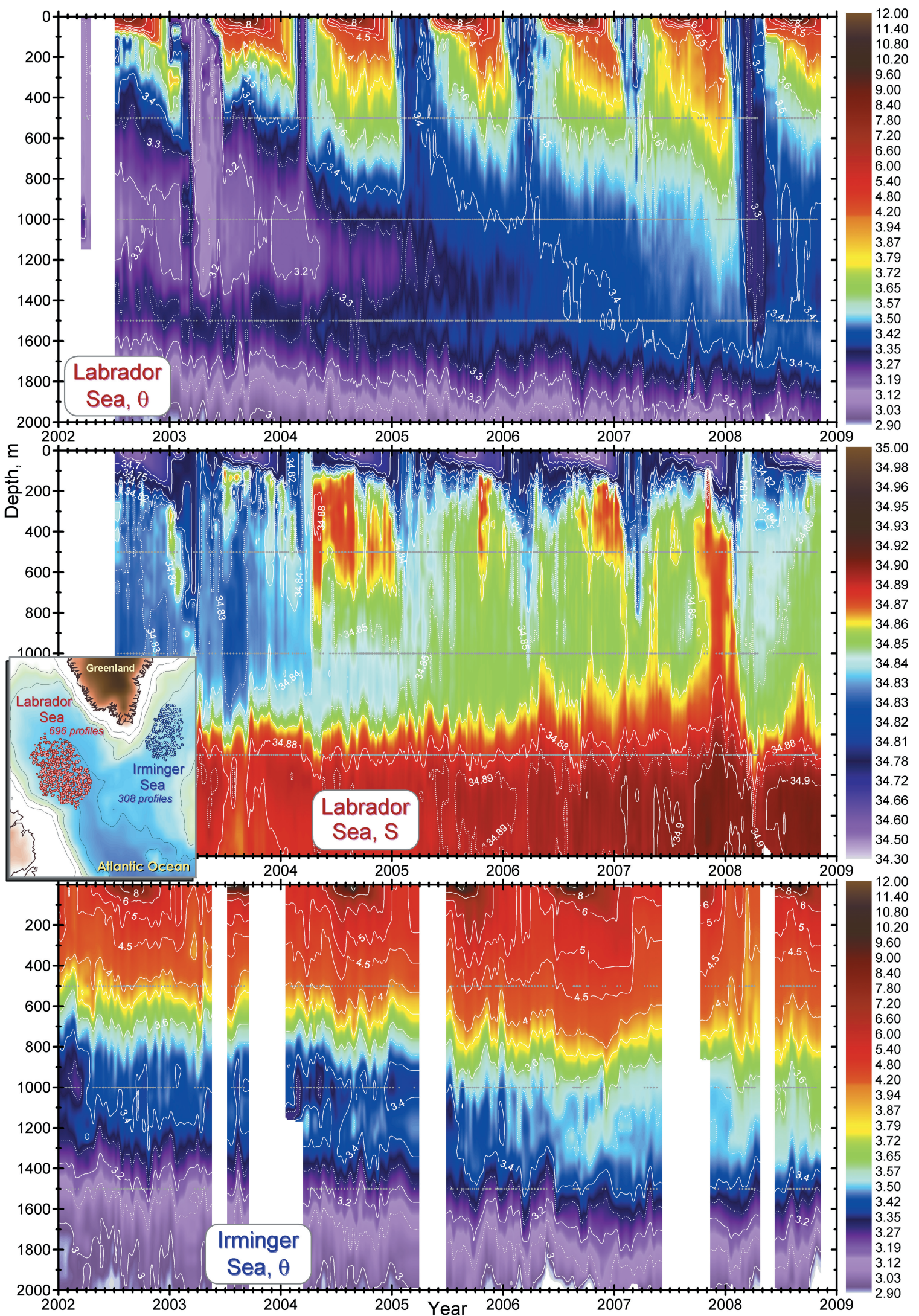

Figure 3. Seasonal-to-interannual development of potential temperature $(\theta)$ and salinity $(\mathrm{S})$ in the central Labrador Sea, and potential temperature $(\theta)$ in the central Irminger Sea, from Argo observations. 


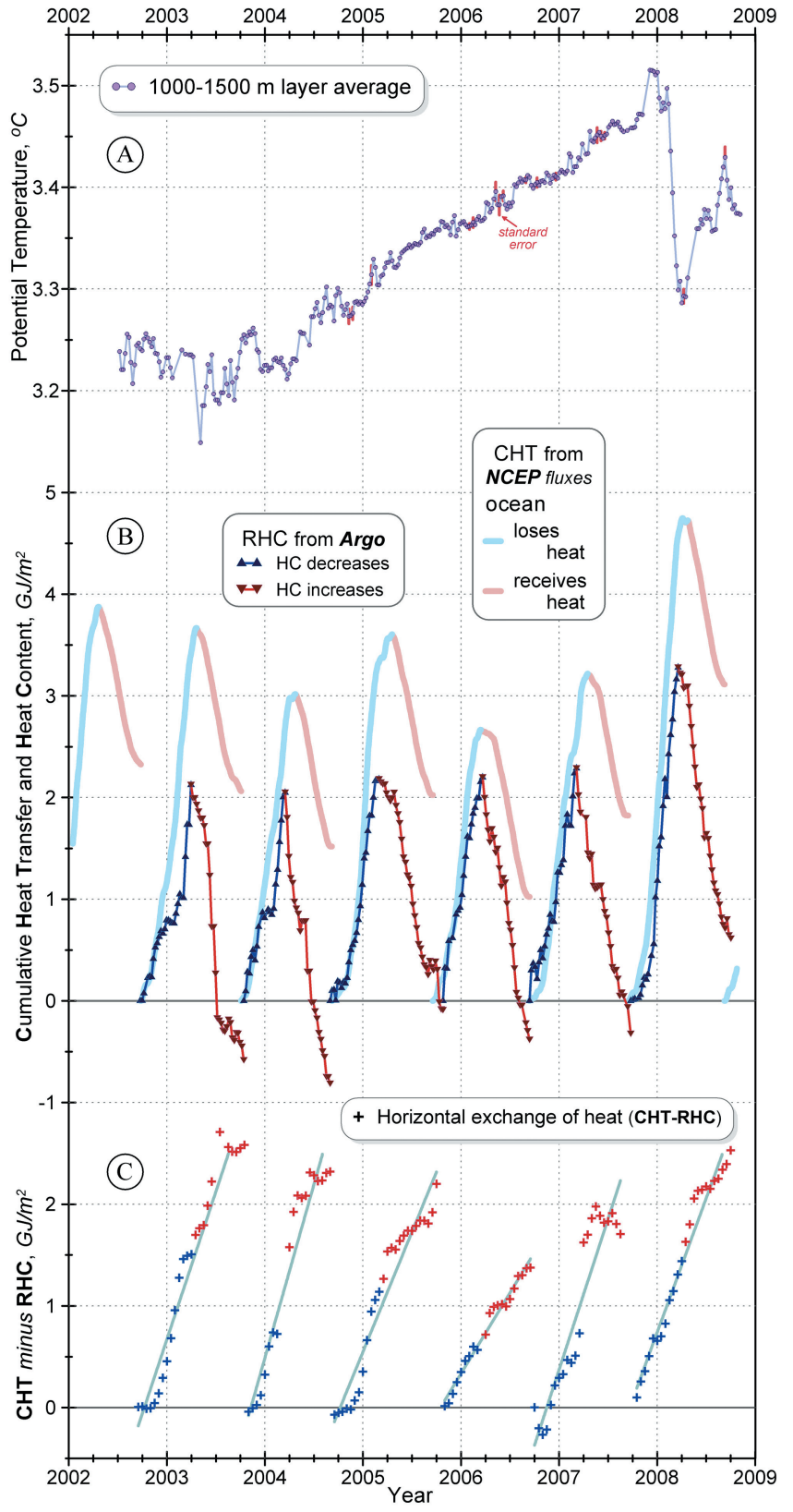

Figure 4. (a) Evolution of the 10-day running mean of the 1000-1500 $\mathrm{m}$ layer average temperatures from the Labrador Sea Argo profiles in Figure 3. (b) The annual cycles of cumulative heat transfer (CHT) through the surface from the NCEP data and Argo-based relative heat content (RHC) in the 10-1600 m layer in the Labrador Sea. The CHT curves start from zero at the time when persistent heat loss (from the ocean) starts each year. RHC is relative to the start of ocean cooling each year and reversed in sign to facilitate comparison with CHT. (c) The differences between CHT and RHC for each cooling/warming cycle. Positive values correspond to heat input to the $10-1600 \mathrm{~m}$ layer in the Labrador Sea, such as via horizontal advection.

[21] There is notable repeatability from year to year in the pattern and relative magnitude of the differences between CHT and RHC (Figure 4c). These differences increase during both the cooling and warming phases of each annual cycle and typically surpass $2 \mathrm{GJ} / \mathrm{m}^{2}$ before the end of it. This is over $60 \%$ of the average magnitude of the cumulative surface heat loss during the cooling phases, and about $35 \%$ more than the cumulative surface heat input during the warming phases. While accurate quantitative conclusions cannot be made (because of the uncertainty in surface fluxes), there is a clear suggestion of a persistent horizontal input of heat to the Labrador Sea interior compensating the excessive annual surface heat loss. The primary sources of this heat appear to be the advection of warm and salty IC water into the region around the southern tip of Greenland and the recirculation of transformed LSW in the inner subpolar gyre (Y2007). The compensating outflow of cooler waters includes the export of newly-formed LSW by the inner gyre, Labrador Current and DWBC. Further investigation of the horizontal exchange contributions to the Labrador Sea's heat budget is clearly required, but the crude estimates of the horizontal fluxes in Figure $4 \mathrm{c}$ do not point to anomalous horizontal heat exchange contributing to the enhanced LSW production in 2008 (this does not rule out a contribution from salt and freshwater fluxes).

\section{Discussion and Conclusion}

[22] The LSW formation to depths near $1600 \mathrm{~m}$ in the winter of 2008 was the largest since 1987-1994 when successive severe winters resulted in convection to $2400 \mathrm{~m}$ and the formation of $\mathrm{LSW}_{1987-1994 \text {. }}$

[23] The Argo observations show that seasonal mixedlayer deepening started in September 2007 and progressed through the fall and early winter, but did not extend to exceptional depths until February 2008. In March deep convection extended to about $1600 \mathrm{~m}$, resulting in the voluminous production of the new $\mathrm{LSW}_{2008}$ class which was prominent in the annual May 2008 AR7W survey.

[24] The availability of Argo data since 2002 confirms that deep convection below $1100 \mathrm{~m}$ in the Labrador Sea had not occurred since 2003 when the $\mathrm{LSW}_{2000}$ (extending to $1300 \mathrm{~m}$ ) was still being modified. Similar data from the Irminger Sea indicates that deep convection there has not extended below $800 \mathrm{~m}$ back to at least 2001, indicating that the Labrador Sea has been the primary ventilation zone for the AMOC in the North Atlantic outside the Nordic Seas so far in this century. The Irminger Sea data do however indicate that remnant $\mathrm{LSW}_{2000}$ was reaching the region during 2002-2005, confirming the recently suggested connectivity of these basins (Y2007a and Y2007b).

[25] The May 2008 survey data suggest that $\mathrm{LSW}_{2008}$ is spreading across the Labrador Sea as expected, overlaying remnant $\mathrm{LSW}_{1987-1994}$ and replacing remnant $\mathrm{LSW}_{2000}$ and warmer waters derived from IC inflows and surface warming.

[26] In part associated with the absence of major LSW production in recent years, the upper and intermediate layers of the Labrador Sea have been steadily warming since 1994 (with the exception of a brief and small interruption associated with $\mathrm{LSW}_{2000}$ ). If enhanced deep convection had not occurred there in 2008, the upper and possibly intermediate layers of the Labrador Sea may have reached record-warm temperatures, exceeding those from the early 1970s (Figure 2). 
[27] The anomalously large heat loss from the ocean to the atmosphere in fall-winter 2007-2008 (Figure 4) provides compelling evidence that atmospheric forcing was the predominant factor in the enhanced production of LSW in 2008, and hence in the disruption of the upper-ocean warming trend. This may be connected with the weak-tomoderate positive anomalies of the North Atlantic Oscillation index in 2007 and 2008 (relative to the 1950-2008 mean), but other factors likely contributed more to the enhanced production in 2008 since these anomalies were not large compared to those associated with previous periods of enhanced convection. For example, the UK MetOffice (http://www.metoffice.gov.uk) reports that the first half of 2008 was the coolest globally since 2000, apparently associated with the presence of a moderate-to-strong La Niña. An analysis of the local atmospheric conditions which potentially contributed to the increased cooling of the Labrador Sea in winter 2008 has recently been presented by Vage et al. [2008].

[28] The origin and significance of the anomalously warm and salty IC water observed over the Labrador Slope in spring 2008 remain unclear and require further investigation. Candidate possibilities for the apparent reduced cooling of the IC water while circuiting the Labrador Sea are reduced interaction with the atmosphere during the cooling season due to ice cover or a fresh surface layer, and anomalously fast transit of the IC water around the Labrador Sea in 2008. The increased density of the water in the upper and mid layers of the central Labrador as a result of the enhanced LSW production should result in increased baroclinic forcing and intensity of the subpolar gyre in 2008. The larger horizontal density gradients on the western side of the Labrador Sea (Figure 1, 300-1000 m, 350-450 km) in 2008 than in 2007 support the possibility of a stronger Labrador Current and the subpolar gyre. It is also possible that the IC water observed over the Labrador Slope in May was much warmer when it entered the Labrador Sea on the Greenland side several months earlier.

[29] The observations described here indicate that substantial oceanographic changes are occurring in the Labrador Sea region. These changes are expected to have implications for the AMOC and potentially larger-scale climate variability. The combination of the annual hydrographic and biogeochemical surveys and continual monitoring by Argo floats provides a much-improved basis for ongoing assessment of ocean climate variability in this important region.

[30] Acknowledgments. The 2008 AR7W survey was conducted by Ocean Sciences and Ecosystem Research Divisions of BIO on CCGS Hudson mission 2008-009. We are grateful to our many colleagues who have contributed to the successful execution of this and preceding surveys and, in particular, to Glen Harrison and Ross Hendry, who have been the Chief Scientists and coordinators of the surveys in recent years. We acknowledge the important contribution of the international Argo program to this work and thank Michael Dunphy for developing algorithms for collating and managing the Argo profiles, Howard Freeland for advising on Argo data transfer, and Allyn Clarke, Ross Hendry, and Dan Wright for helpful comments on the paper.

\section{References}

Clarke, R. A., and J.-C. Gascard (1983), The formation of Labrador Sea Water. Part I: Large-scale processes, J. Phys. Oceanogr., 13, 1764-1778. Lazier, J. R. N., R. M. Hendry, R. A. Clarke, I. Yashayaev, and P. Rhines (2002), Convection and restratification in the Labrador Sea, 1990-2000, Deep Sea Res., Part A, 49, 1819-1835.

Pickart, R. S., F. Straneo, and G. W. K. Moore (2003), Is Labrador Sea Water formed in the Irminger Sea?, Deep Sea Res., Part I, 50, $23-52$.

Talley, L. D., and M. S. McCartney (1982), Distribution and circulation of Labrador Sea Water, J. Phys. Oceanogr., 12, 1189-1205.

Våge, K., R. S. Pickart, V. Thierry, G. Reverdin, C. M. Lee, B. Petrie, T. A. Agnew, A. Wong, and M. H. Ribergaard (2008), Deep convection returns to the subpolar North Atlantic, Nature Geosci., in press.

Yashayaev, I. (2007), Hydrographic changes in the Labrador Sea, 1960 2005, Prog. Oceanogr., 73, 242-276, doi:10.1016/j.pocean.2007.04.015. Yashayaev, I., and R. R. Dickson (2008), Transformation and fate of overflows in the northern North Atlantic, in Arctic-Subarctic Ocean Fluxes: Defining the Role of the Northern Seas in Climate, edited by R. R. Dickson, J. Meincke, and P. Rhines, pp. 505-526, Springer, New York. Yashayaev, I., H. M. van Aken, N. P. Holliday, and M. Bersch (2007a), Transformation of the Labrador Sea Water in the subpolar North Atlantic, Geophys. Res. Lett., 34, L22605, doi:10.1029/2007GL031812.

Yashayaev, I., M. Bersch, and H. M. van Aken (2007b), Spreading of the Labrador Sea Water to the Irminger and Iceland basins, Geophys. Res. Lett., 34, L10602, doi:10.1029/2006GL028999.

J. W. Loder and I. Yashayaev, Fisheries and Oceans Canada, Bedford Institute of Oceanography, P.O. Box 1006, Dartmouth, NS B2Y 4A2, Canada. (yashayaevi@mar.dfo-mpo.gc.ca) 